\title{
O REAL E A HISTÓRIA
}

\section{O RETORNO DO REAL}

de Foster, Hal. Tradução de Célia Euvaldo. São Paulo: CosacNaify, 2014.

\section{OTAVIO LEONIDIO}

[1] Smithson, Robert. "Ultramodern". Arts Magazine, v. 42, $\mathrm{n}^{\circ}$ 1, set.-out. 1967, p. 31. Minha tradução.
Os problemas em torno dos quais O retorno do real se constitui são imensos. Eles têm pautado o pensamento e a prática de críticos e artistas desde meados dos anos 1960-ou seja, há exatamente meio século; de um modo ou de outro, e sobretudo no que concerne à questão do significado da arte dita contemporânea, dizem respeito a uma questão crucial: a crise da concepção de história sobre a qual a arte vinha sendo (e, parcialmente pelo menos, ainda vem sendo) produzida desde o romantismo. Mais especificamente, a questão central de O retorno do real é a eventual superação de um "historicismo persistente que julga a arte contemporânea atrasada, redundante e repetitiva" (p.30). Em certo sentido, portanto, Foster se vê aqui às voltas com os mesmos desafios e dilemas de uma geração de artistas e críticos que, como afirmou um de seus maiores expoentes, Robert Smithson, percebeu que "uma consciência transistórica emergiu nos anos sessenta"

A agenda de Foster não coincide, todavia, com a dos artistas sessentistas. Pois o que está em jogo para ele é também, e talvez sobretudo, a viabilidade de uma modalidade discursiva (a crítica de arte) que, desde o romantismo, busca o significado das obras de arte na interseção entre qualidade estética (vinculada à noção transcendental de experiência estética) e pertinência histórica (vinculada à situação das obras de arte no quadro geral da História da Arte). Ou seja, o que está em jogo para Foster são as condições de possibilidade de um discurso crítico cujos fundamentos em larga medida coincidem com o próprio advento (em fins do século XVIII) do historicismo - precisamente os fundamentos que a arte dos anos 1960 pôs em xeque. Quer dizer, diferentemente do que ocorre com boa parte da práxis artística dos anos 1960 e 1970, Foster pretende salvaguardar a prática crítica tradicional. Como? Dotando-a de um vocabulário conceitual 
"pós-histórico" (p. 25) não apenas operativo mas igualmente legitimável num ambiente de crescente desprestígio das "grandes narrativas" - as históricas, sobretudo².

A solução encontrada por Foster lança mão do conceito de "neovanguarda", compreendido aqui de modo idiossincrático, i.e., em termos da noção de "Nachträglichkeit" ("efeito a posteriori" ou, literalmente, "ação retardada"). Tomada de empréstimo à teoria psicanalítica, a noção supõe que "um evento só é registrado por meio de outro que o recodifica; só chegamos a ser quem somos no efeito a posteriori (Nachträglichkeit)". Toda a argumentação de Foster parte pois da hipótese de que "a vanguarda histórica e a neovanguarda são constituídas de maneira semelhante, como um processo contínuo de protensão e retenção, uma complexa alternância de futuros antecipados e passados reconstruídos" (p. 46). Nessa perspectiva, supostamente cairia por terra o argumento (levantado por Peter Bürger em Teoria da vanguarda, contra o qual O retorno do real explicitamente se volta) 3 de que a arte dos anos 1960 se restringiria a uma repetição farsesca e acrítica das ações empreendidas pelas chamadas vanguardas históricas. Para Foster, ao contrário, a neovanguarda dos anos 1960 consistiria na plena efetivação daquilo que apenas de modo incompleto ou inacabado foi empreendido no início do século XX por movimentos como construtivismo, dadaísmo e surrealismo.

Obviamente, pode-se arguir o rendimento heurístico do modelo psicanalítico proposto por Foster, quer dizer, questionar em que medida ele constitui de fato um ganho de conhecimento sobre a arte dos anos 1960. Significativamente, a questão élevantada pelo próprio autor, o qual, numa nota de pé de página desconcertante, admite que "[a]inda que eu combine o desenvolvimento com o efeito a posterio$r i$ minha extensão da (re)construção do sujeito individual até a (re) construção de um sujeito histórico é problemática". Donde a dúvida: "Será que posso abordar historicamente a lógica do sujeito se meu modelo da história pressupõe essa lógica? Esse vínculo duplo seria produtivo ou paralisante".

O fato de Foster ter ido adiante com seu modelo psicanalítico (sem o qual este livro não existiria) não dá por encerrada a questão. De fato, em termos epistemológicos, o livro apenas explicita os dilemas de uma geração de intelectuais progressistas que, tendo sido formada num ambiente francamente desconstrutivista, viu-se nos anos 1980 (ou seja, num contexto em que grassavam sem resistência institucional tanto Aids quanto Reaganomics) à procura de um aparato teórico porventura menos irrealista que o desconstrutivismo. A advertência de Foster acerca dos limites de sua própria empreitada intelectual,voluntariamente destinada a resgatar não todo e qualquer real, mas apenas a uma reconstrução subjetiva sua ${ }^{4}$, soa nesse sentido duplamente
[2] Lyotard, J-F. A condição pós-moderna. Rio de Janeiro: José Olympio, 2004 .

[3] Bürger, Peter. Teoria da vanguarda. São Paulo: CosacNaify, 2008. 
sintomática: por um lado, evidencia um incontido desejo de realidade; por outro, denuncia o mal-estar para com a própria noção de realidade - ao menos com relação àquelas noções de realidade que, advertidamente ou não, possam evocar uma referencialidade minimamente estável. Mais do que um dilema, a posição de Foster expõe a condição porventura aporética do projeto pós-pós-modernista, do qual Foster é um avatar. Significativamente, no capítulo final de O retorno do real, Foster se pergunta acerca das desconstruções operadas por Foucault e Derrida: "Esses pós-estruturalismos reelaboram os acontecimentos do pós-colonial e do pós-moderno criticamente? Ou servem de ardis por meio dos quais esses acontecimentos são sublimados, deslocados ou, ao contrário, desativados?" (p. 199). Enredado numa espécie de limbo epistemológico, Foster - como muitos de nós, aliás - procura abrigo num mundo pós-transcendental particularmente inóspito a desconstrutivistas não irrealistas e sobretudo não pluralistas (avessos portanto ao "falso pluralismo do museu, do mercado e da academia pós-históricos" [p.7]).

O que a solução proposta por Foster revela, no entanto, é um vício de origem - qual seja, a suposição de que, como queria Bürger, a arte dos anos 1960 caracterizar-se-ia por um resgate (aos olhos de Bürger, acrítico e anacrônico, aos de Foster, deliberado e pertinente, porquanto produto de uma inusitada e lúcida "consciência histórica") de práticas próprias às "vanguardas históricas". De fato, nas palavras de Foster, "os artistas da década de 1960 tiveram de elaborar [os procedimentos da vanguarda histórica] criticamente; a pressão da consciência histórica não permitia nada menos do que isso" (p.25). Este, de fato, o pressuposto não problematizado de O retorno do real: dar por suposto (contra inúmeras evidências de que o que de fato caracteriza a arte dos anos 1960 não é em absoluto o predomínio de uma consciência histórica, senão a emergência e disseminação de uma consciência meta ou anti-histórica) que a questão crucial para a neovanguarda seria "remodela[r] procedimentos da vanguarda para fins contemporâneos" (p. 8). Como se vê, a divergência de Bürger é apenas parcial, a diferença residindo no modo como um e outro interpretam um mesmo fenômeno, Bürger condenando-o, Foster exaltando-o.

Os limites insuperáveis de O retorno do real vêm daí. A começar pela evidente dificuldade do autor de dar conta da arte com a qual, aparentemente, tem maior empatia - o minimalismo. Pois se de um modo ou de outro o minimalismo (mas também uma parte importante da arte produzida em sua esteira) põe em xeque a ideia de vanguarda (em função justamente da consciência de seus vínculos com a visão de mundo historicista), Foster se revela incapaz de conceber quaisquer práticas artísticas "ambiciosas" que não sejam igualmente "avança- 
das" ou "inovadoras" (passim), ou seja, que não suponham a noção de "desenvolvimento histórico". Dito de outro modo, o que Foster não parece estar pronto a conceber (a exemplo de Bürger) e mais ainda aceitar é - parafraseando T.J. Clark - uma arte sem futuro5. Donde o descompasso: ali onde uma parte significativa da arte dos anos $1960 \mathrm{e}$ 1970 buscava conjurar uma experiência temporal meta-histórica (em cujo contexto o conceito de vanguarda simplesmente não faz sentido), Foster se empenha a todo custo em preservar a ideia e o valor não apenas da vanguarda, mas acima de tudo de uma historicidade supostamente inerente à arte - em suas palavras, a "historicidade de todas as artes, incluindo a contemporânea" (p.33). De par com essa historicidade essencial, o que Foster pretende salvaguardar é a criticalidade da arte - mais especificamente, a criticalidade histórica da arte. Uma vez mais, estamos diante de uma posição axiomática. Pois, aos olhos de Foster, simplesmente não há criticalidade num ambiente em que predomina a "desatenção à historicidade" e no qual, portanto, a crítica resulta marcada pela "perda de influência histórica" (p.13).

Os pressupostos modernistas dessa salvaguarda da historicidade da arte (e com ela de uma crítica baseada num conceito supostamente renovado de "desenvolvimento histórico", não mais progressista e teleológico) são evidentes: com a noção de neovanguarda o que se quer preservar é uma tradição: a tradição do novo, i.e., de uma ideia de arte segundo a qual, como afirmou um de seus mais influentes praticantes - Harold Rosenberg -, "ter um lugar na história da arte é o valor"6.

Obviamente, Foster não há de concordar com essa leitura; de toda evidência, ele está convencido de que seu modelo alternativo de desenvolvimento histórico foi de fato capaz de complexificar categorias fundamentais como "causalidade", "temporalidade" e "narratividade" (cap. 1, passim), e, assim, superar o modelo historicista de desenvolvimento, na qual a narrativa modernista se baseia. Até onde percebo, no entanto, o que Foster logrou superar não foi propriamente o modelo historicista, mas uma versão bastante simplória deste.

Não que Foster ignore a complexidade dos problemas teóricos com os quais está lidando aqui. Notadamente, o autor está a par da centralidade que aqui adquire a noção de evento - o fato de que, como adverte Zizek, uma das referências teóricas de Oretorno do real, "o ponto crucial aqui é o status modificado do evento"7. Mas aqui também fica claro como o diálogo com Bürger resultou pouco produtivo. Pois a noção de evento que Foster pretende complexificar, tomada emprestada de Bürger, não vai muito além daquela que subjaz à boutade marxiana de que "todos os grandes acontecimentos da história mundial ocorrem duas vezes, a primeira como tragédia, a segunda como farsa" (p. 32). A escolha de Foster é curiosa - mesmo de parte um intelectual marxista; surpreende sobretudo que Foster tome como contramodelo
[5] Clark, T.J. Por uma esquerda sem futuro. São Paulo: Ed. 34, 2013.

[6] Rosenberg, Harold. "O novo como valor". In: _. Objeto ansioso. São Paulo: CosacNaify, 2004.

[7] Zizek, Slavoj, apud Foster, p. 46, n. 42. Minha tradução. 
[8] Koselleck, Reinhart. Futuro passado: contribuição à semântica dos tempos históricos. Rio de Janeiro: Ed. PUC-Rio; Contraponto, 2006.

[9] Arendt, Hannah. "O conceito de história: antigo e moderno". In: Entre o passado e o futuro. São Paulo: Perspectiva, 1988, p. 96. uma noção tão estereotipada de evento histórico - noção que ignora a evidência de que o traço principal da noção de evento no contexto do historicismo não é nem a originalidade nem a autonomia, senão, conforme a formulação de Reinhart Koselleck, o fato de estar sempre pronto a "alterar sua identidade em função do status cambiante que

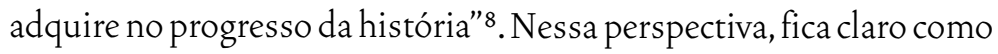
a noção de evento que Foster deriva de Marx (na qual, em parte pelo menos, se baseiam os realismos de ume de outro) deixa de lado a questão central do significado dos eventos num contexto epistemológico (o historicismo) comandado pela noção de "processo" - mais especificamente, por um processo que, como percebeu Hannah Arendt, "torna por si só significativo o que quer que porventura carregue consigo, adquirindo assim um monopólio de universalidade e significação"9. A suposição de que Foster logrou complexificar as noções de evento e, por conseguinte, de desenvolvimento histórico é, como se vê, enganosa. O que Foster complexificou foi um par de estereótipos.

A opção de Foster por operar a partir de tal contramodelo não é injustificada, contudo; ela se adéqua à perfeição a uma argumentação que pretende requalificar historicamente as neovanguardas, vistas não mais como repetição farsesca mas, alternativamente, como plena realização histórica. Uma vez mais, fica claro quão limitada é a divergência de Bürger. Pois a leitura de Foster permanece atravessada pelas noções - e, além dessas, pelos valores - tipicamente modernistas de autenticidade e originalidade. Afinal, o que Foster pretende sustentar por meio de seu modelo alternativo de desenvolvimento senão a tese de que as neovanguardas não são farsescas e espúrias? A argumentação de Foster é, de fato, sem ambiguidade: se as neovanguardas repetem eventos históricos, isso se deve ao fato de que, de acordo com o conceito de "efeito a posteriori", sua primeira manifestação/ocorrência se restringiria apenas a uma dimensão incompleta, reprimida. Em vez de mera repetição, sua segunda ocorrência nos anos 1960 seria portanto da ordem do desrecalque de algo que por trinta, quarenta anos havia permanecido reprimido. O que a teoria de Foster sustenta, portanto, é a ideia de que, em sua integridade e plenitude, as ações retardadas da neovanguarda constituem um evento histórico autêntico, original, verdadeiramente vanguardista. Ora, mas uma posição de fato meta-historicista não deveria, ao contrário, simplesmente descuidar das noções de autenticidade e originalidade, não obstante os enormes problemas que esse deslocamento coloca para um sistema de arte dependente - hoje como ontem - da ideia de vanguarda?

O que Foster não é capaz de conceber, em revanche, é uma história que não seja desenvolvimental, isto é, que não se oriente naturalmente em direção ao futuro - mais especificamente, a um futuro entendido como "horizonte de expectativa", i.e., como campo aber- 
to a transformações mais ou menos utópicas. Dito de outro modo, desenvolvimento é compreendido aqui não como categoria adstrita a um regime de historicidade específico (o historicismo), senão como condição antropológica e transistórica, e nesse sentido insuperável, da experiência temporal humana. Como se vê, o argumento em favor de uma "historicidade de todas as artes" tem uma origem definida.

Que a defesa de um marxismo renovado (em contraste com o marxismo alegadamente ossificado de Bürger) esteja no centro da reflexão de Foster não é, como se vê, fortuito: é sempre preservar a ação historicamente empenhada - isto é, a ação empreendida na e para a "História" - aquilo que está em jogo aqui. Para Foster, afinal, prática artística ambiciosa é também, necessariamente, prática engajada. Dito de outro modo, aos olhos de Foster o que cabe à práxis artística não diverge muito do que cabe à ação política:viver nofront da História, fazer com que esta avance, combater a ameaça de estagnação. O pressuposto tem, é claro, um desdobramento no âmbito da crítica: se não se faz arte ambiciosa fora da História, o mesmo se dá com respeito à crítica. Esta, de fato, a função precípua, e a decorrente legitimidade, da crítica modernista (mas também, como se vê, da crítica supostamente pós-modernista de Foster), cuja principal incumbência, na prática, é de fato a atribuição da situação histórica das obras, quer dizer, a definição do lugar preciso ocupado pelas obras de fato avançadas e inovadoras em cada etapa do "desenvolvimento histórico". Tanto quanto a práxis artística, a atividade crítica deve pois obedecer ao preceito de que "a compreensão histórica não depende do apoio contemporâneo, mas um engajamento no presente, seja artístico, teórico e/ou político, é indispensável" (p.11).

Mas, repare-se: tanto quanto o "engajamento no presente", o argumento supõe um "presente" definido essencialmente como tempo e espaço de "engajamento", quer dizer, como tempo e espaço de uma ação historicamente engajada e transformadora. Ora, como destacou Hans U. Gumbrecht, tal concepção do presente é um dos pressupostos mais básicos, ainda que tácitos, do historicismo. Segundo Gumbrecht, é de fato apenas no contexto do regime temporal historicista que "em cada momento presente, o sujeito deve imaginar uma gama de situações futuras que têm de ser diferentes do passado e do presentee dentre as quais ele escolhe um futuro de sua preferência"; se contexto que a "subjetividade pode integrar o componente de ação na autoimagem que ela oferece à humanidade. E é essa inter-relação entre tempo e ação que cria a impressão de que a humanidade é capaz de 'fazer' sua própria história". Coerentemente, é também apenas nesse contexto que o tempo, compreendido como agente absoluto de mudança, "dá à inovação o rigor de uma lei compulsória"1o. Como fica claro, modernismo e consciência histórica (mas também marxismo)
[10] Gumbrecht, Hans U. “Cascatas de modernidade", In: _. Modernização dos sentidos. São Paulo: Ed. 34, pp. 15-16. 
[11] Clark, T.J., op. cit. Minha tradução.

[12] Cf. Fried, Michael. “Arte objetidade". A/E Revista da Pós-Graduação em Artes Visuais, Rio de Janeiro, EBA-UFRJ, 2002, pp. 130-147.

[13] Wagner, Anne M. "Reading minimal art". In: Battcock, Gregory.Minimal art: a critical anthology. Berkeley: University of California Press, 1995.

[14] Ver, em especial Krauss, Rosalind. "Sense and sensibility: reflection on post ' 6 os sculpture. Artforum, v. $12, \mathrm{n}^{\circ} 3$, nov. $1973, p p \cdot 43-53$. são astros de uma mesma constelação epistemológica, em cujo centro jaz o regime de historicidade historicista. O que tal evidência expõeéo tamanho dos desafios que a crise do historicismo coloca para a crítica "progressista". Pois o que está em jogo neste caso é nada menos do que a viabilidade não apenas de uma esquerda sem futuro (nas palavras de Clark, uma esquerda apta a "não ver uma forma ou uma lógica - um desenvolvimento desde o passado até o futuro", e que portanto diz adeus às "reflexões [afterthoughts] e imagens da vanguarda") ${ }^{11}$, mas de uma esquerda historicamente desengajada, ou pelo menos eventualmente disposta a engajar-se numa concepção alternativa de história. Não por acaso, Foster conclui $O$ retorno do real indagando-se em que medida um sujeito pós-moderno disfuncional (o sujeito "suspenso entre a proximidade obscena e a separação espetacular") não se limitaria a obedecer à lógica de "uma razão cínica [que] não elimina mas renuncia ao poder de ação [agency]" (p.206).

Que o apego de Foster à episteme modernista/historicista constitui tanto a marca registrada quanto os limites de O retorno do real fica evidente na afirmação de que Michael Fried (como se sabe, o grande detrator do minimalismo) 12 "é um excelente crítico do minimalismo não porque tem razão em condená-lo, mas porque, para ser persuasivo, tem de entendê-lo, e isso significa entender sua ameaça ao modernismo tardio" (p. 66). A tese é absurda; Fried jamais compreendeu o minimalismo, fenômeno que ele - como tantos outros depois dele, aliás - se restringia a ver do ponto de vista de sua suposta objetidade literal, uma visão que, como destacou Anne M. Wagner, é francamente reducionista ${ }^{13}$. O que tal afirmação deixa claro, no entanto, é a afinidade entre os fundamentos vanguardistas (e portanto modernistas/ historicistas) das práticas críticas de Fried e Foster.

Não surpreende, nesse sentido, que, não obstante a ressalva que faz à ênfase excessivamente fenomenológica que Rosalind Krauss dá ao minimalismo ${ }^{14}$, Foster tenda sempre a ver o minimalismo como expressão essencialmente fenomenológica e de tipo site specific (específico do lugar) - em suas palavras, como uma arte na qual o espectador "é instigado a explorar as consequências perceptivas de uma intervenção particular num determinado local [site]. É esta reorientação fundamental que o minimalismo inaugura" (p.53). Que tal definição (afeita à obra tipicamente antiminimalista do segundo Robert Morris, mas também aos objetos e operações fenomenológicos de um Richard Serra) implica uma redução absurda do significado da obra crucial de Donald Judd é uma das consequências do enviesamento conceitual/ ideológico de Foster. Que ela não acomode, ou acomode de modo canhestro, no espaço minimalista a obra essencialmente antifenomenológica e anti-site specific de Robert Smithson, é outro. Numa chave psicanalítica, pode-se dizerque,em sua busca pelo desrecalque do real, 
Foster acabou reprimindo o real minimalista - algo, a liás, que Joseph Kosuth já havia destacado com respeito às construções historiográficas perpetradas ainda nos anos 1970 pelo grupo de críticos ao qual Foster está ligado, a começar por Krauss. De fato, como afirmou Kosuth, "a fácil assimilação do minimalismo no mainstream como mais um tipo de forma na história da escultura constitui basicamente a limpeza [cleansing] de seu peso filosófico"15.

Nada disso diminui a importância de O retorno do real. Publicado originalmente em 1996, mas contendo partes fundamentais apresentadas ainda em meados dos anos 1980, o livro deixa claro como as questões levantadas pela arte dos anos 1960 ainda pautam, e em grande medida assombram, a arte e a crítica atuais. Nesse sentido, a importância do livro está menos em seus achados que no modo como revela, ainda que involuntariamente, os desafios e dilemas que a crise do conceito moderno de história coloca para o pensamento crítico (ou metacrítico) contemporâneo, o de Hal Foster inclusive. Em tempo: a presente edição conta com tradução de Célia Euvaldo, especialmente eficaz na manutenção da fluidez da leitura ${ }^{16}$.
[15] Kosuth, Joseph, "History for". Flash Art, Milão, no 143, nov.-dez. 1988, p. 101. Minha tradução.

[16] Agradeço a leitura e os comentários de Marcelo G. Jasmin, Felipe Charbel e Henrique Estrada.

Recebido para publicação em 19 de abril de 2015.

\section{NOVOS ESTUDOS}

\section{CEBRAP}

101, março 2015

pp. $175-182$ 